\title{
DESIDERIO NAVARro E A TRAdUÇÃo DA TEORIA CRÍtICA RuSSA EM CUBA
}

\section{Desiderio Navarro Y LA TRAducción De La TeOrÍa CRÍTICA RuSA EN CUBA}

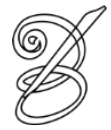 \\ Raúl E. Colón Rodríguez \\ Doutorando em Tradutologia - École de traduction et d 'interprétation / Université d'Ottawa - Ottawa, Ontário, \\ Canadá) \\ raulecolonr@yahoo.com \\ Traduzido por: \\ Patrícia Rodrigues Costa \\ (Doutoranda em Estudos da Tradução / PGET/UFSC) \\ Prcosta1986@gmail.com \\ Rodrigo D'Avila Braga Silva \\ (Mestrando em Estudos da Tradução, POSTRAD/UnB) \\ rodrigodavilabraga@gmail.com
}

\section{Introdução}

Desiderio Navarro é um politradutor ${ }^{\mathrm{i}}$ cubano que traduziu desde os anos de 1960 uma enorme quantidade de textos teóricos russos e da Europa do leste, em particular textos contrários ao conformismo marxista que tomou conta do poder nesses países. Navarro pôde fazê-lo apesar dos obstáculos impostos pela doxa neostalinistaii na ex-URSS e em Cuba. Também publicou uma obra teórica inspirada em diversos textos teóricos euro-orientais e ocidentais traduzidos por ele.

Este artigo pretende responder questões relativas à trajetória desse tradutor, contextualizadas as duas tendências fundamentais que o caracterizam: de um lado, a luta permanente contra as doxas nacionais e internacionais, e, de outro, um esforço sustentado pela difusão de novas teorias e ideias, estimulando a interdisciplinaridade entre a criação teórica e artística cubana. Navarro se apropria da teoria crítica russa por meio da tradução, pois o faz em 
um contexto geopolítico particular. Os fatores culturais e o posicionamento político do tradutor são aqui elementos-chave que não devem ser menosprezados.

De acordo com os postulados da tradutologia assim designados (BASALAMAH, 2005, p.60): visibilidade, ética e responsabilidade cidadã do tradutor, desejo ampliar estas finalidades para o trabalho de pesquisa, pois considero que a visibilidade ideológica do que é apresentado ao leitor é tão necessária ou ainda mais do que aquilo é descrito e criticado. Este texto contém uma visão crítica da história de Cuba e da atualidade da ilha, sendo como eu mesmo um resultado diferente, mas igualmente imposto por esta realidade, assim como é o tradutor e a obra aqui analisada.

Para contextualizarmos, é necessário apontar qual foi o fator de interesse deste tema. Entre 2006 e 2007, em decorrência da saída de Fidel Castro da vida pública devido à saúde precária, ocorreu uma troca vigorosa de correios eletrônicosiii entre os intelectuais cubanos de diversas gerações, os quais protestavam contra uma contraofensiva à doxa ideológica e político-cultural do governo herdado por Raúl Castro. Navarro desempenhou um papel fundamental como promotor e organizador desse protesto, além de desempenhar um papel importante como representante dos intelectuais e intermediários junto ao poder.

No geral, a obra de Navarro é pouco conhecida no Canadá e na América do Norte e se atualmente a presença de um autor na Internet é um critério de sucesso e reconhecimento ${ }^{\mathrm{iv}}$, o caso de Navarro mostra que, apesar do impacto de seu trabalho, este segue sendo uma entidade quase invisível (VENUTI, 2008 [1995]). Inclusive na Europa ${ }^{\mathrm{v}}$, onde o conjunto de sua obra foi reconhecido em 2009 com a entrega do prêmio da Fundação Príncipe Claus da Holanda.

O estudo acerca da trajetória de um intelectual crítico, ou em termos bourdieusianos, de um agente avi $^{v i}$ é ao mesmo tempo tradutor e teórico, é orientado a contribuir com o conhecimento de sua obra e com debate em torno dela. Esta é uma obra que no contexto de Cuba e da América latina hispânica e lusófona, há mais de 50 anos, teve e tem uma influência que tende a aumentar ${ }^{\mathrm{vii}}$.

O corpus analisado se limita à tradução para o espanhol realizada por Desiderio Navarro de uma parte da teoria literária e linguística pouco ortodoxa acerca do espaço russo-soviético do século passado. Entre os autores mais célebres traduzidos por Navarro podemos citar: Baktin, Medvedev, Lotman, Ivanov, Meletinsky e Groys, de um total de aproximadamente 20 autores 
russos. A análise se limita aos 33 textos da antologia do pensamento russo ${ }^{\text {viii, }}$ publicada recentemente em Cuba. Contudo, um total de 115 textos sobre a teoria russa foi traduzido por Navarro durante toda a sua carreira.

O tema tratado pode primeiramente preencher um vazio na história da tradução nas Américas (o Caribe como espaço geográfico concreto e a tradução contemporânea como domínio específico). Em segundo lugar, deveria permitir uma melhor compreensão das formas, às vezes inesperadas, que toma a tradução de teorias em certos países e observar a influência que este tipo de tradução tem na América Latina. É importante esclarecer as implicações diretas e indiretas na ação social. Essa temática também está presente na atualidade, quando se considera publicações recentes na tradutologia, nas quais o ativismo social do tradutor é analisado e até elogiado, mas igualmente criticado ${ }^{\mathrm{ix}}$.

Nossa hipótese é de que a tradução em Cuba de teorias críticas russas com um caráter antiortodoxo, como feito por Navarro, é uma tradução transcultural inserida num contexto antineocolonial $^{\mathrm{x}}$. A problemática por sua vez explorada é de poder analisar como essas traduções têm estimulado e incentivado o surgimento de uma mudança social em Cuba.

\section{Trajetória e tradução da teoria crítica russa}

Desiderio Navarro nasceu em 13 de maio de 1944 na província centro-oriental cubana de Camagüey, a qual tem uma larga tradição cultural e intelectual (UNESCO, 2005). De origem mestiça, Navarro foi educado na tradição católica conservadora e desenvolveu, como a maioria dos intelectuais dos anos de 1940 e 1950 em Cuba $^{\text {xi }}$, um espírito de resistência à imposição de dogmas religiosos. Com a vitória da revolução de 1959, Navarro se integrou à reorganização da vida cultural em sua província natal. Começa seus estudos universitários interrompidos em razão da campanha a anticatólicos que ocorreram nos centros de estudos superiores cubano, sob a égide de um "aprofundamento da consciência revolucionária" xii. Começou, então, sua formação autodidata na área de línguas ${ }^{\text {xiii }}$, pela qual se lança na carreira de tradutor. A partir de 1968, Navarro viveu e trabalhou em Havana.

O processo de formação intelectual de Navarro é duplo. De um lado, ele está comprometido com o turbilhão revolucionário, resultando num doutrinamento marxista, que nessa etapa mostra evidências de ortodoxia. De outro lado, compromete-se também com o movimento 
contestatório de diversos intelectuais cubanos, contra o dogmatismo que se instaurou progressivamente na vida social cubana, sendo este último espírito a prevalecer na atividade tradutória e social de Navarro desde o final da década de 1960 até hoje. Navarro é um intelectual crítico para a situação nacional e um intelectual nacionalista perante a situação internacional, em particular no que concerne às relações de Cuba com os Estados Unidos e o mundo ocidental.

Em seu livro publicado em 2007, "La política cultural del período revolucionario: memoria y reflexión" (NAVARRO, 2007b), o tradutor e teórico cubano define quatro períodos fundamentais da política governamental cubana para com a atividade crítica dos intelectuais no espaço público. Essa política é por ele definida como "gerenciamento da memória do esquecimento" que reprimia por vias diretas e indiretas a atitude crítica dos intelectuais:

"[...] podemos decir que las intervenciones y espacios críticos de «los 60 (1959-1967) fueron borrados en «los 70» (1968-1983); los «errores» políticoculturales cometidos contra esas intervenciones y espacios en «los 70» fueron superficialmente reconocidos e inmediatamente borrados en «los 80»(1984-1989); y por último, las nuevas intervenciones y espacios críticos de «los 80» fueron borrados en los 90" (Navarro, 2007b:21-22).

[...] podemos dizer que as intervenções e os espaços críticos dos "anos 60 [1959 - 1967] foram esquecidos nos anos 70" [1968 - 1983]; os "erros" político-culturais cometidos contra essas intervenções e espaços nos "anos 70" foram superficialmente reconhecidos e imediatamente excluídos nos "anos 80" (1984 - 1989); e por último, as novas intervenções e espaços críticos dos "anos 80" foram eliminados nos "anos 90". (NAVARRO, 2007b, p. 21-22).

Verificamos com Navarro a linha central e constante da política castrista em relação ao papel dos intelectuais na sociedade cubana: mantê-los sob controle e monitoramento constante, de modo a impedir por todos os meios uma participação ativa e crítica nos assuntos sociais que possam afetar o capital simbólico e, sobretudo, político desse governo. Toda ação provoca uma reação, assim Navarro desde o início dos anos 1970 contribui com a criação da revista Criterios.

Porém, 1968 é um ano de difícil definição para Cuba. É o ano em que se introduz profundas mudanças sociais, a princípio de ordem econômica, com a eliminação da pequena empresa, mediante uma onda de nacionalizações ${ }^{\text {xiv }}$. Essa política global de "agravamento na luta de classes durante a construção do socialismo" e a necessidade de combater sem piedade os “inimigos do povo" foi a contribuição de Stalin à teoria marxista-leninista ${ }^{\mathrm{xv}}$. 
Os neoestalinistas cubanos inspirados nos mesmos pressupostos ideológicos dos russos e soviéticos, sob o comando de Stalin, e dos chineses, sob o comando de Mao, aplicam esse princípio político às condições de Cuba em 1968. A chamada "ofensiva revolucionária" deixou uma marca permanente no povo cubano. No campo político-cultural se impôs também uma espécie de desapropriação do papel social a todo um setor da população. Os intelectuais críticos, mesmo aqueles que eram favoráveis às mudanças revolucionárias, tornaram-se alvo dessa nova política. Começa nessa época o que o intelectual cubano Ambrosio Fornet chamava de "Quinquênio cinza" (FORNET, 2007b, p. 25-46). No entanto, não devemos nos isolar do contexto internacional ao analisar esses acontecimentos, os quais ocorreram em Cuba logo após a "Primavera de Praga", na qual a participação dos intelectuais foi decisiva. Castro havia apoiado incondicionalmente a invasão soviética (CASTRO, 1968) e a influência do país aos soviéticos foi reforçada em Cuba a tal ponto que se pode falar de sovietização, e do início de uma nova, mesmo que relativa, dependência neocolonial em Cuba entre 1968 e 1991, ano da queda da União Soviética.

Nesse contexto, extremamente delicado do ponto de vista político e caracterizado por um equilíbrio de forças tenso e complexo entre o poder e os intelectuais críticos, é que Navarro cria Criterios, em fevereiro de $1972^{\text {xvi }}$. Esse projeto inaugura e consolida lentamente uma produção editorial que estreia com uma primeira antologia de traduções: Textos $y$ contextos, em $1986^{\text {xvii }}$, e é seguida por uma coleção editorial de Criterios $^{\text {xviii }}$. Mais de uma centena de traduções de Navarro-Criterios são compartilhadas com outras revistas culturais cubanas. Suas traduções de teóricos do Leste são incluídas em antologias de outras editoras cubanas e também publicadas no exterior, em especial na Espanha e México.

Em sua palestra principal no ciclo de debate acerca da "política cultural do período revolucionário", posterior aos acontecimentos de 2006-2007, Navarro explicita as motivações que teve ao criar essa revista de tradução de teorias:

«Los que vieron en el parecido semántico-lexical una relación de familia entre los
nombres de Criterios y Pensamiento Crítico, no se equivocaron. Los que vieron una
relación de catálisis en la irrupción de Criterios tan sólo siete meses después de la
desaparición de Pensamiento Crítico, tampoco se equivocaron» (Navarro, 2007b:16).
Aqueles que viram na semelhança semântico-lexical uma relação familiar entre os
nomes Criterios e Pensamiento Crítico, não se enganaram. Os que viram uma

COLÓN. Desiderio Navarro e a tradução da teoria crítica russa em Cuba

Belas Infiéis, v. 2, n. 2, p. 99-125, 2013. 
relação de catálise no surgimento de Criterios somente sete meses após o fechamento de Pensamiento Crítico tampouco se enganaram. (NAVARRO, 2007b, p. 16)

Criterios tentou, de maneira enigmática ${ }^{x i x}$, ser uma continuação de Pensamiento Crítico $^{x x}$, pois precisava se adaptar às circunstâncias. A tradução de autores russos não-ortodoxos publicados juntamente aos ortodoxos foi para Navarro uma opção válida para transmitir um mínimo de diversidade teórica. Nesse contexto de censura forçada, Navarro explica suas opções:

Sólo el aprovechamiento de la conjunción del culto de la URSS y - en menor medida del campo socialista en general, por una parte, y la ignorancia total de las «vacas sagradas» teóricas del pavonato ${ }^{21}$ sobre qué pasaba realmente con tales o cuales autores y teorías en esos países, por la otra, me permitió publicar durante dos años trabajos clásicos o artículos introductorios del formalismo ruso, la semiótica soviética y el neostructuralismo checo [...] » (Navarro, 2007b:16)".

Somente com o uso da conjunção do culto da URSS e, em menor medida, do campo socialista em geral, por um lado, e a ignorância total dos teóricos consagrados do Pavonato ${ }^{\mathrm{xxi}}$ sobre o que se passava realmente com tais autores e teorias nestes países, de outro, me permitiram publicar trabalhos clássicos ou artigos introdutórios sobre o formalismo russo, a semiótica soviética e o neoestruturalismo tcheco durante anos. (NAVARRO, 2007b, p.16)

Em 1974, a revista sofreu seu primeiro fechamento após a chegada em Cuba de conselheiros soviéticos da área da cultura, portadores das "orientações politicamente corretas". Criterios reabre no final dos anos 1970 sob a tutela da UNEAC ${ }^{\text {xxii }}$, mas se vê ameaçada por um novo fechamento em 1980, quando a direção desta instituição toma conhecimento de um artigo no qual Navarro critica o realismo socialista dogmático. Somente em 1983, outra instituição, a Casa de las Américas ${ }^{x x i i i}$, passa a proteger Navarro e a revista Criterios, permitindo que ele trabalhe $\mathrm{e}$ sobreviva. Durante a segunda metade dos anos 1980 e no decorrer do período que coincide com o que Navarro chama de "novas intervenções e espaços críticos dos anos 80" (NAVARRO, 2007b, p. 21-22), Criterios organiza dezenas de conferências de pesquisadores cubanos e estrangeiros. Colóquios e encontros nacionais e internacionais também foram organizados com a participação de dezesseis teóricos de nove países e a realização de mais de cinquenta conferências de renomados pesquisadores como: Lotman, Jameson, Culler, Prince, Pavis, Ivanov e Pfister. A 
rede internacional de Criterios e de Navarro estava bem estabelecida no final dos anos 1980, algo que será fundamental para a subsistência do projeto na década seguinte.

A trajetória deste tradutor, no decorrer desses anos, permite constatar que a tradução da teoria cultural crítica russo-soviética permitiu-lhe criar as condições de uma resistência, primeiramente teórica e gradualmente artística e social, na medida em que suas traduções eram estudadas e citadas no ensino universitário, particularmente por professores e estudantes do centro de estudos menos influenciado pelo dogmatismo reinante; refiro-me ao Instituto Superior de Arte (ISA) em Havana.

Resistências teóricas, artísticas e sociais são unidas em simbiose em uma ética de resistência, às vezes com êxito, porém mais frequentemente encontra obstáculos a cada passo, contudo sempre com a vontade de continuar na direção escolhida, porque a alternativa havia sido o fracasso do seu projeto de vida, para não mencionar uma responsabilidade moral em torno daqueles que se baseavam em seu trabalho.

Em resumo, observamos o desenvolvimento de uma ética de resistência por parte de Navarro, que enfrenta problemas de formação, dificuldades e contradições internas, ideológicas, políticas e cognitivas; somando-se a tudo isso um certo desgaste provocado pelo tempo e que favorece o questionamento a posteriori por parte de seus contemporâneos ou por parte de alguns jovens críticos que buscam seu lugar na vida pública cubana por meio de métodos, também, pouco ortodoxos ${ }^{\mathrm{xxiv}}$. Apesar disso, o trabalho de Navarro e de Criterios até o momento e de maneira geral pode ser considerado inigualável e incomparável.

Os anos 1990 foram marcados pelo que Castro classificou eufemisticamente de “período especial em tempos de paz", espécie de terminologia paramilitar para se referir a uma profunda crise socioeconômica, após a perda de um parceiro estratégico. Nes se contexto político nacional e internacional, ocorreu uma mudança qualitativa no trabalho de Navarro e da revista Criterios, editada por ele.

Dois textos do programa ${ }^{\mathrm{xxv}}$ podem ser consultados no sítio da página da revista Criterios, os quais testemunham a passagem gradual de Navarro de uma posição crítica, antes discreta, para uma posição mais abertamente crítica, em relação ao ambiente no qual desenvolve sua atividade de tradução e transmissão de ideias. Navarro critica 
ferrenhamente nesses textos o leitmotiv de Castro $^{\text {xxvi }}$, o qual tem guiado a política cultural do país. Ele descreve as relações entre a classe política cubana e os intelectuais da ilha nos últimos 40 anos. Navarro também estabelece uma cronologia a respeito do encontro entre os políticos que consideram a classe intelectual como "um outro ideológico real que os interpela nos espaços públicos a respeito de questões nacionais extraculturais e políticas” (NAVARRO, 2006, p. 13). Navarro define o ano de 1968, nesse texto, como um ano de ruptura entre os políticos "revolucionários" no poder e os intelectuais, favoráveis às mudanças sociais, porém críticos a quem as operam.

"In Medias Res Publicas: Sobre los intelectuales y la crítica social en la esfera pública cubana" (NAVARRO, 2006 [2000]) custa a Navarro uma punição oficial que ele reconhece abertamente no segundo texto na página de apresentação no sítio da revista, trata-se de "Criterios in medias res publicas" (2002). O texto de 2000 significou para Critérios e para Navarro o local prometido pelo poder cubano para institucionalizar e consolidar o esforço editorial e sociocultural da revista (NAVARRO, 2002, p.12).

No ano de 2003, Navarro toma uma nova decisão importante. Sem a ajuda material do Estado $^{\text {xxvii }}$, porém beneficiando-se de uma onda de criação de novas ONGs no país, consegue criar uma que representa seu projeto. Com uma autorização geral, mas controlada pelo poder, cria o Centro teórico-cultural Criterios, que até hoje está aos cuidados do $I C A I C^{x x v i i i}$ e da Casa de las Americas.

O desafio a que submeteram Navarro, rechaçando-o do direito de institucionalizar seu projeto e de obter o reconhecimento nacional, foi aceito por ele porque o tradutor cubano não redirecionou seu trabalho em direção a um confronto aberto com o poder, o que prova sua perseverança e astúcia ao dar continuidade ao seu trabalho por outros meios, diferentes daqueles oferecidos pelo Estado em condições draconianas. No entanto, a criação de uma ONG deve ser feita conferindo vínculo institucional com este mesmo Estado. As duas instituições que apadrinharam a ONG têm por função evitar que esta seja considerada um "elétron livre" e que proíbam simplesmente a Navarro ser uma figura pública.

O Centro teórico-cultural Criterios surgiu numa conjuntura na qual pôde ser favorecido pelo apoio de organismos internacionais, os quais na Cuba da década de 1990 são importantes atores na materialização de projetos culturais alternativos. Esse centro, a partir do nono andar do 
edifício do ICAIC, desenvolverá uma intensa atividade de tradução, de promoção de conferências com pesquisadores convidados, cubanos e estrangeiros, e de apoio às diferentes áreas das artes.

Como mencionado antes, o ano de 2007 foi decisivo para Criterios e para Navarro, uma vez que ambos são claramente considerados capital simbólico. Dito isso, é necessário informar que as condições cubanas desse tipo de capital não são garantia de segurança inabalável, de sucesso e de continuidade sem os obstáculos de um projeto cultural. Entretanto, Navarro sempre soube utilizar sua crítica que flutuava conforme as circunstâncias e apoios estratégicos com os quais contava nas diversas esferas do poder e essas duas instituições que apadrinhavam o Centro serviam de exemplo a ser lembrado.

Além disso, Navarro no papel de organizador e fornecedor de trocas de correspondências críticas em 2007, desempenha igualmente na continuação desses eventos um papel importante de mediador com o poder e de organizador, nos meios intelectuais e artísticos, da decorrente reflexão. O ciclo de conferências organizado por Criterios será o ponto alto em torno da reflexão sobre "a política cultural no período revolucionário", título dado ao período de discussões e ao livro publicado posteriormente (NAVARRO, 2007b). Sua apresentação nesse contexto constitui uma contribuição teórica importante para o debate dos intelectuais cubanos nesse período. Existem duas razões importantes para se afirmar isso: primeiramente, porque ela oferece quatro modelos de sociedade e da cultura na luta em Cuba daquela época e de hoje. Esse é o questionamento teórico-político mais importante proposto por ele até aquela data, já que enfrenta um tema político mais global e complicado que afeta os cubanos, ou seja, que tipo de sociedade estamos construindo? Em segundo lugar, porque esse texto é retomado com frequência no debate intelectual em Cuba (ARANGO, 2010) e entre cubanos exilados ou, em geral, na América latina (CHAGUACEDA, 2010).

Em “¿Cuántos años de qué color? Para una introducción al Ciclo” (NAVARRO, 2007b, p.15-24), Navarro enumera e descreve quatro modelos de sociedade e de cultura que se encontram em luta "não somente na escala macrossocial, mas muitas vezes dentro de uma mesma cabeça" (NAVARRO, 2007b, p.19-20):

1. lo que Marx llamó « comunismo de cuartel » (monismo artístico : exigencia de un arte apologético y acrítico, el artista sólo como entretenedor, ornamentador o ilustrador de tesis); 2. socialismo democrático (diálogo artístico, con inclusión y fomento de un arte crítico-social); 3. capitalismo de Estado o «socialismo de mercado» (pluralismo 
artístico, con exclusión de un arte crítico-social, apertura a la globalización americanocéntrica y fomento de la cultura destinada al mercado transnacional y nacional); 4. capitalismo neoliberal (sumisión del arte al mercado transnacional y nacional; neutralización y recuperación de un eventual arte crítico-social por el mercado). (NAVARRO, 2007b:20)

1. O que Marx denominou de "comunismo de quartel" (monismo artístico: exigência de uma arte apologética e acrítica, o artista somente como um animador, ornamentador ou ilustrador da tese); 2. Socialismo democrático (diálogo artístico, com inclusão e fomento de uma arte crítico-social); 3. Capitalismo de Estado ou "socialismo de mercado" (pluralismo artístico com exclusão de uma arte crítico-social, abertura à globalização 'americanocêntrica' e fomento da cultura destinada ao mercado transnacional e nacional); 4. Capitalismo neoliberal (submissão da arte ao mercado transnacional e nacional; neutralização e recuperação de uma possível arte crítico-social pelo mercado). (NAVARRO, 2007b, p.20)

Não é difícil compreender qual desses quatro modelos é compartilhado por Navarro. Evidentemente, trata-se do segundo, que até hoje nunca foi posto em prática, aquele de um socialismo democrático onde o artista e o intelectual recuperariam o papel perdido como elemento crítico e de mediador/conciliador do debate social. Portanto, podemos observar que de uma descrição das relações entre o poder e os intelectuais críticos (NAVARRO, 2006 [2000]), Navarro passa a fazer um questionamento cabal do modelo de sociedade na qual está inserido, algo que sem dúvida é muito mais arriscado, tanto do ponto de vista ideológico quanto político.

Mas, Navarro, assim como Trotsky na sua época, é um profeta desarmado (DEUTSCHER, 1996 [1959]). Contudo, a obra de Navarro, assim como foi a do revolucionário russo para a compreensão da história contemporânea de seu país, e, particularmente, o ativismo social do tradutor cubano, cercado por teorias, que tem traduzido, contribuíram e contribuem imensamente para o entendimento da realidade cubana contemporânea. Essa obra promove também uma análise irrestrita dos problemas cubanos atuais e futuros. Navarro não é o único em Cuba que promove um socialismo democrático, mas a pergunta que se faz imediatamente é se esses cubanos poderiam quebrar o muro da hostilidade imposto pelo poder atual e se poderiam se converter um dia em uma opção política. Nada permite considerar essa opção como viável atualmente.

Retornando à história da tradução, e concluindo estas ideias, podemos dizer que a tradução de teorias e o ativismo social estão intimamente ligados no caso de Navarro. Objetivamente, ou seja, independentemente de suas ideias políticas, sempre proclamadas por ele como Marxistas, Navarro defende um marxismo crítico e aberto ao debate, continua beneficiando- 
se do capital simbólico que esta teoria política mantém no contexto cubano. Esta poderia ser uma das razões pela qual Navarro decidiu disponibilizar esses 33 textos da antologia do pensamento russo. As circunstâncias concretas, particularmente em relação ao ano de 2009, quando o debate intelectual tinha espaço em Cuba e quando a Rússia era convidada à Feria internacional del libro de La Habana, reforçam esse critério.

É importante também recordar o fato de que a tradução de teorias implica, no caso de Navarro, em um trabalho teórico subsequente. Tema já estudado em um sentido contrário, ou seja, quando a produção de teoria envolve o ato de traduzir, é o caso dos textos filosóficos em particular, (MESCHONNIC, 1999, p. 386), o foi porém menos naquilo em que estamos interessados, ou seja, quando traduzir teoria implica em produzir teoria. Navarro é um caso singular, mas esperamos que não seja o único.

\section{De tradutor de teorias a teórico}

A publicação em 2009 da antologia "El pensamiento cultural ruso em criterios", pode ser considerada como a resposta simbólica de Navarro aos seus antigos oponentes, detentores atualmente de um capital simbólico decadente, mas ainda fortes em seu poder real. O prólogo da obra é um paratexto exaustivo do tradutor/editor, e representa uma reinterpretação da história cultural cubana, na qual ele foi parte ativa. Em Cuba, nas mais altas esferas do poder, ouviu-se com frequência um discurso de "retificação", mas essa "retificação" foi transformado, muitas vezes, em um "esquecimento programado do passado" com uma continuação das mesmas tendências, executado desta feita por outros funcionários, com outras palavras para nomeá-las, e em circunstâncias diferentes. Mudar tudo para que nada mude! Exclamou o Gattopardo de Lampedusa.

Utilizando a terminologia bourdieusiana ${ }^{\mathrm{xxix}}$, Navarro analisa a problemática da correlação de forças no seio do campo cultural cubano. Ali faz justiça às contribuições de outros intelectuais cubanos que também têm lutado com os seus próprios meios contra a imposição do realismo socialista no movimento literário cubano. (Navarro, 2009, vol.1:xix) ${ }^{\mathrm{xxx}}$. Navarro inclusive mostra, através da recepção da obra de Bakhtin em Cuba, que o mundo editorial cubano impedia a publicação de obras do grande teórico russo, não porque estivessem seguindo as orientações do aparato cultural brejneviano, que começava já nos anos 70 a outorgar honras e reconhecimentos a 
este autor, mas porque o critério de censura era a biografia política dele, e o fato de que ela, como a de outros tantos autores marxistas antiortodoxos russos e do Bloco do Leste, estava "manchada" pelas perseguições e prisões do período de Stalin.

É por esse motivo, e pela filiação política que revelara, que Navarro qualifica esses atores da vida cultural da ilha como: "estalinistas cubanos [que] nunca aceitaram tais reabilitações que contradiziam a vontade do onisciente e infalível Secretário Geral" (Navarro, 2009, vol.1:xxi).

A crítica de Navarro não se limita à política cultural cubana. Ele igualmente guia a sua caneta contra o etnocentrismo em sua versão russocêntrica. A crítica ao etnocentrismo já havia inspirado outros de seus textos teóricos (Navarro, 2007a:151-188), mas neste ele transforma, pela primeira vez, em objeto de crítica as tipologizações e periodizações propostas por "certos professores cubanos e soviéticos" que aplicavam de maneira arbitrária fórmulas da cultura russa aos processos e fenômenos da cultura cubana. Navarro se revela aqui em sua faceta de autor antineocolonial, não apenas como um representante do "antineocolonialismo oficial", dirigido contra os Estados Unidos, mas também e, sobretudo, contra o neocolonialismo no campo cultural, exercido pelo império russo-soviético em Cuba.

O tradutor enfrenta geralmente uma complexidade extrema que caracteriza o texto teórico. Coloca-se diante dele a atenção ao detalhe terminológico, um conhecimento necessário da obra do filósofo e teórico que se traduz e do contexto que o cerca para produzir essa obra; e um conhecimento total ou pelo menos parcial da obra dos autores e teóricos com os quais, quem é traduzido tem estado ou segue estando em acordo ou desacordo. É igualmente necessário um conhecimento geral da história da filosofia ou da história das teorias. Na maior parte do tempo é indispensável um aparato paratextual, o qual o tradutor deve produzir, para deixar explícito nas línguas e nos textos de chegada os significados que estão implícitos nas línguas e textos de partida.

O paratexto do tradutor também é necessário para deixar compreensíveis significados que foram destinados a um público erudito, ou seja restrito, porque como constata Simon, "il y a dans la logique même de leur écriture [les théoriciens qu'on traduit] un refus de la transparence qui se répercute dans l'activité de la traduction" (há na própria lógica de sua escrita [dos teóricos que traduzimos] uma rejeição da transparência que repercute na atividade de tradução (Simon,1991:11). O tradutor não tem outra opção a não ser produzir "significados novos", no 
entanto parece legítimo questionar-se, como fazê-lo? Quais são as circunstâncias (espaçotemporais) desse "movimento de transferência"? Quais são as implicações, por exemplo, das "traduções tardias" ou dos conceitos "intraduzíveis"? (Simon, 1991:11-12).

Para analisar as questões que seguem, o método proposto por Edgar Morin se mostra útil no nosso caso. A imagem preferida de Morin para explicar o princípio da recursión organizacional é o do turbilhão, onde cada momento é produto e produtor. Segundo Morin, "Un processus récursif est un processus où les produits et les effets sont en même temps causes et producteurs de ce qui les produit. " (Um processo recursivo é um processo onde os produtos e os efeitos são ao mesmo tempo causas e produtores daquilo que os produz), (Morin, 2005 [1990]:99-100). Esse princípio nos parece aplicável ao processo da tradução geral, já que o tradutor não pode impedir as idas e vindas entre o texto, língua e cultura ${ }^{\mathrm{xxxi}}$ de origem e de chegada, introduzindo conscientemente ou não elementos de uma tríade na outra. Esse princípio é particularmente aplicável à tradução de teorias e à teorização. Pode-se pensar que na medida em que a tríade é complexa (como é o caso da teoria), muito mais presente se revelará o princípio da recursividade. Isso é verificado com Navarro. Podemos constatar, por exemplo, que desde o ponto de vista quantitativo, quanto mais recentes eram as traduções de Navarro nessa antologia, mais numeroso era o seu aparato paratextual ${ }^{\text {xxxii. }}$. De maneira similar se comportou a natureza qualitativa das notas do tradutor, quanto mais recentes eram estas, mais frequentes eram as referências provenientes de outras línguas que não eram nem o espanhol nem o russo. Não foi somente a erudição do tradutor que aumentou com o tempo, foi também a evolução de seu método de trabalho no momento de traduzir teoria, um método que se enriqueceu ao mesmo tempo em se tornou mais complexo.

É por isso que podemos considerar que a tradução de teorias se diferencia da tradução literária, da poesia ou também do gênero literário do ensaio por uma série de elementos próprios: 1. A novidade ou originalidade cognitiva dos temas tratados no texto de partida; 2 . A profusão de neologismos que tentam nomear e/ou explicar as zonas da realidade recentemente descobertas e/ou novamente interpretadas; 3 . A ausência na tríade de chegada de antecedentes dos elementos precedentes $^{\mathrm{xxxiii}}$.

Tradução de teorias e trabalho teórico são certamente fatores interdependentes no caso de Navarro, mas este último é também produto de uma identidade transcultural comum aos seus 
concidadãos. É igualmente o resultado de um processo sociopolítico de caráter antineocolonial no qual o tradutor está imerso permanentemente.

\section{Transculturação e antineocolonialismo}

A necessidade de considerar um eixo teórico-prático coletivo, ou seja, uma abordagem contextual e sociológica ao estudar os termos, o que, por extensão, pode ser aplicado à tradução de teorias, é um tema já levantado pelos tradutólogos ${ }^{\text {xxiv }}$ (Bronwlie, 2002). Edwin Gentzler expôs três dimensões fundamentais para a realização de pesquisas sobre tradução nas Américas (Gentzler, 2008:4).

Analisaremos duas destas dimensões: a primeira é a psicológica; ela tem a ver com a identidade nacional dos cubanos, que é uma identidade transcultural ${ }^{\mathrm{xxxv}}$, produto de uma história comum nas Antilhas: conquista, escravização de africanos, plantación, indústria açucareira, imigração europeia, caribenha entre outras. Em Imperial Eyes: Travel Writing and Transculturation (2008 [1992]), Mary Louise Pratt foi uma das primeiras a estabelecer o vínculo entre a transculturação e os conceitos do pós-colonial e o neocolonial ${ }^{\mathrm{xxxvi}}$.

A segunda dimensão proposta por Gentzler é a sociopolítica, diretamente vinculada ao contexto atual da ilha. O traço que melhor caracteriza sua linha geopolítica geral é o antineocolonialismo $^{\text {xxxvii }}$, uma resistência política e igualmente intelectual à condição neocolonial que produz o império estadunidense. Esse traço sintetiza um tipo de pensamento onipresente no discurso político-cultural cubano do último meio século. No caso da produção teórica de Navarro, podemos defini-la como de caráter antineocolonialista, nacionalista e de filiação marxista antiortodoxa.

A terceira dimensão segundo Gentzler, a geográfica, está implícita no caso aqui estudado, pois Navarro, como todos os cubanos, pertence a uma cultura fronteiriça (border culture), e esse é também o caso de outras sociedade caribenhas (Gentzler, 2008:3).

A perspectiva da tradução-apropriação como "tendência dominante da tradução na América latina" (Bastin, 2004, 2010) xxxviii encontrou aceitação entre os tradutólogos que estudam o subcontinente latino americano. Ela constitui aqui o elemento principal que nos permite realizar a ponte entre "transculturação" e "tradução", já que a apropriação de textos de outras línguas e culturas é um procedimento intimamente ligado à transculturação. O outro elemento é o caráter 
performativo (Tymoczko, 2007:125) das traduções de teorias de Navarro, não no sentido formal (criação de novos estilos literários, por exemplo), mas no sentido de uma mobilização do pensamento crítico nos receptores dessas traduções.

A importância e o papel da tradução no processo de transculturação em Cuba são observáveis no trabalho de Navarro. Se, a partir de 1959, a tradução contribui globalmente para a instrução massiva da população cubana, fortalecendo a integração de diferentes setores sociais, pois estes se beneficiam, em princípio, das mesmas oportunidades, é, no entanto, a tradução de teorias, da qual Navarro é de alguma forma "figura de proa", que com muito mais frequência do que ele desejava, contribuirão com forçada discrição para o desenvolvimento de uma intelligentsia crítica e de uma crítica cidadã complementar. Esse trabalho tem sido realizado dessa maneira porque ainda existe uma tensa correlação de forças entre as culturas e grupos da sociedade cubana. A transculturação, em uma redefinição contemporânea, foi classificada como o processo em que um grupo social ou "une culture a tendance à dominer l'autre" (uma cultura tem tendência a dominar a outra), (Benessaieh, 2010:3). Ou seja, por trás de um discurso unitário repetido sobre a identidade cubana por parte do partido no poder em Cuba, o que vemos é uma pequena burguesia, principalmente branca e "revolucionária", em seus mais altos escalões do poder, impondo sua visão de qual deve ser a cultura a se promover e divulgar, e, sobretudo, impondo sua linha política ao resto da população, onde $34,9 \%$ é composta por negros e mestiços ${ }^{\mathrm{xxxix}}$.

A intencionalidade performativa das traduções teóricas ganham pouco a pouco força no contexto cubano. Navarro trabalha para contribuir com esse propósito com os meios de que dispõe, as alianças que o permitem subsistir e que permitem manter funcionando o Centro Criterios, as intransigências que marcam momentos de ruptura estratégica e as concessões táticas que desorientam os detentores da doxa. Navarro contribui também com a seleção de textos que faz a cada momento, ao levar a seu público novas ideias para mobilizar a crítica.

A revolução cubana coloca Navarro em um turbilhão de ações militantes que o faz desenvolver um ativismo social permanente. $O$ tradutor cubano exercita um ativismo de resistência para o exterior e de crítica para o interior do país, marco de uma correlação de forças exterior e interior sempre sob tensão. São estes dois componentes e o contexto de seu modo de ação que permitem definir seu posicionamento sociopolítico, como fora feito anteriormente. $\mathrm{O}$ impacto das traduções militantes, portadoras de um posicionamento anticolonial está fortemente 
ligado às circunstâncias históricas e às tendências de desenvolvimento sociocultural da sociedade em que elas ocorrem. Esse trabalho intelectual tem favorecido no contexto cubano uma exceção que, embora confirme a norma na qual a tradução é frequentemente "serva" do poder, aos poucos a corrói, pois cria as condições para a mudança e a transição para uma nova ordem social. O posicionamento antineocolonial navarrino não é unidirecional nem monocromático, politicamente falando, mas se seu discurso antineocolonial promove uma ideologia marxista antidogmática, é também portador de outra ideologia muito presente no âmbito cubano: o nacionalismo ${ }^{\mathrm{xl}}$. Esta ideologia política, tardia no contexto cubano, como a própria independência, ocorrida em 1902, é um conjunto de ideias sistemática e amplamente utilizadas por todos os setores da vida política da ilha. Nesse contexto, nos parece pertinente recordar a crítica dos nacionalismos que fez o intelectual francês Guy Scarpetta:

«Il faut d'abord noter que la notion même de nationalisme est pour le moins ambigüe : il y a le nationalisme des colonisateurs qui répriment et celui des colonisés qui s'affranchissent, il y a un nationalisme porteur d'espoir, de libération, et un autre (parfois le même) susceptible de reconduire de nouveaux asservissements, de nouvelles aliénations »(1981:22-23).

Deve-se notar que a própria noção de nacionalismo é, no mínimo, ambígua: existe o nacionalismo dos colonizadores que reprime e o dos colonizados que se libertam, há um nacionalismo portador de esperança, de libertação e outro (às vezes o mesmo), capaz de nos levar de volta para novas servidões e novas alienações.

Outro autor que fez uma crítica ao nacionalismo em sua variante cultural foi o filósofo alemão Wolfgang Welsch. Em um artigo a respeito da análise do que ele considera o processo de transculturalidade, em curso na escala global, que se opõe a conceitos parciais como globalização ou particularização, e especificamente sobre a historicidade das culturas, escreveu:

\footnotetext{
"Cultures were to reside strictly within themselves and be closed to their environment. But as we know, such folk-bound definitions are highly imaginary and fictional; they must laboriously be brought to prevail against historical evidence of intermingling; and they are, moreover, politically dangerous, as we are today experiencing almost worldwide". (Welsch, 1999:2)

As culturas foram pensadas para serem estritamente autossuficientes e fechadas a influências externas, mais como sabemos, essas definições regionais ou étnicas circunscritas são altamente ilusórias e fictícias, elas devem ser laboriosamente persuasivas para prevalecer contra a evidência histórica da mestiçagem e também são politicamente perigosas como podemos constatar hoje, em quase todos os lugares.
}

COLÓN. Desiderio Navarro e a tradução da teoria crítica russa em Cuba Belas Infiéis, v. 2, n. 2, p. 99-125, 2013. 
Essas ideias nos parecem pertinentes para a análise crítica de qualquer nacionalismo, nesse caso o cubano, porque esse contribuiu na etapa contemporânea, tanto para aumentar a autoconsciência nacional e o reconhecimento internacional da cultura cubana, como favoreceu um retrocesso identitário, uma arcaização do pensamento e um atraso crônico do debate social.

Reconhecer os limites do seu posicionamento sociopolítico e antineocolonial nacionalista e marxista, mesmo tratando-se de um marxismo antiortodoxo, ainda está fora do alcance dos intelectuais cubanos comprometidos da ilha (incluindo Navarro). Como os outros, ele adere a uma visão acrítica dos valores nacionalistas, seguindo a regra não escrita, mas tacitamente observada segundo a qual, diante do altar da unidade nacional e da ameaça externa, sacrifica-se o debate sobre o que significa "nação" no contexto cubano.

\section{Conclusão}

O pensamento e a ação de Navarro, materializados em sua tradução e apropriação da teoria critica russa, contribuíram para a formação da consciência crítica de várias gerações de intelectuais e artistas cubanos. Esses textos estimularam e contribuíram para a mudança social em Cuba e estão hoje indissoluvelmente ligados à condição transcultural da identidade cubana. Nesse sentido, essas traduções têm sido portadoras de neoculturação, (Ortiz, 1991 [1940]:90).

O contexto histórico e cultural cubano, a história da tradução em Cuba, a trajetória do tradutor, o corpus de textos estudado, o trabalho do Centro Teórico-Cultural Criterios e sua projeção internacional, são todos elementos que possuem uma relação recursiva com a identidade transcultural do tradutor, bem como com o seu posicionamento sociopolítico e com o ativismo social estreitamente relacionado às principais apostas socioculturais do país. Sem essas condições, a obra de Navarro seria outra, ou não teria sido. Navarro é, portanto, um "produto cubano" dos últimos cinquenta anos.

Considerar essas condições permite ter um melhor domínio cognitivo dessa realidade e nos permite aproximarmo-nos muito mais de sua complexidade. De fato, a fim de compreender melhor as correntes subterrâneas da tradução de teorias, ou seja, o que as motiva e as põe em circulação em uma determinada região do mundo, é necessário estabelecer quais dos elementos estudados têm um caráter duradouro e quais têm um mais temporário, conservando sempre como referência uma escala espaço-temporal humana. A tradução nas Antilhas e particularmente em 
Cuba é marcada por fortes elementos indentitários e sociopolíticos, que podem ser associados aos processos de particularização que ocorrem no mundo em desenvolvimento, em resposta à globalização neoliberal (Welsch, 1999:10). A identidade e um ou outro posicionamento sociopolítico são constantes observáveis no Caribe. Esses são os elementos duradouros que persistem ao longo da história e da vida de várias gerações e refletem nitidamente na cultura e na tradução. As crenças, ideologias, preconceitos, declarações, manifestos, etc., são elementos de caráter temporal, que certamente podem estabelecer-se por muito tempo na consciência social do povo, mas que também podem variar dentro do espaço-tempo de uma única geração.

Posterior à publicação da antologia aqui analisada (2009), Navarro continua o trabalho de difusão de pensamentos diversos que permitem uma aproximação complexa da realidade. O projeto 1001 textos do Centro Teórico-Cultural Criterios já lançou sua terceira edição em 30 de novembro de 2010. Em Cuba circulam hoje 3003 textos traduzidos para o espanhol por Navarro e outros tradutores, e também em suas línguas originais (inglês, francês e etc.), com direitos cedidos por seus autores para circulação gratuita. Na comemoração de 40 anos da revista Criterios (2012), Navarro criou um novo Serviço informativo bimestral de pensamento cultural europeu difundido através da lista de correios eletrônicos do centro. Trata-se fundamentalmente de uma atualização, para o público cubano, do pensamento cultural desse continente ${ }^{x l i}$. Um Serviço informativo sobre o pensamento cultural da América do Norte também está nos planos, aguardando fontes de financiamento.

Esses elementos apontam para o reconhecimento no debate intelectual, do papel antidogmático e mobilizador que tem a tradução de teorias em Cuba, e por extensão na América Latina. O estudo de caso de Navarro mostra finalmente que o tradutor, no âmbito internacional, pode escapar da dicotomia, sem saída aparente, ou ser um instrumento do discurso imperialista ou opor a ele uma partidária e ardorosa resistência. Através da tradução de teorias, o tradutor fornece visões críticas da realidade e constrói pontes de entendimento que podem afastar os seus leitores das identidades mortíferas, (Maalouf, 2001 [1998]) que assolam em maior grau os países pobres e dependentes.

O tradutor na esfera nacional e local pode intervir como mediador na correlação de forças internas entre o intelectual crítico e o poder, promovendo o conhecimento, graças a seu trabalho, e às experiências e ideias de outros lugares. Esse tipo de intervenção contribui para a formação de 
valores cívicos, de conhecimentos científicos e de aportes culturais que incidem em uma adaptação-interação não conflituosa com um mundo que simultaneamente se globaliza e se particulariza, ou seja, se transculturaliza, (Welsch, 1999).

\section{REFERÊNCIAS BIBLIOGRÁFICAS}

ACOSTA, Rinaldo (2009). « Ediciones de Literatura Teórica extranjera en Cuba. Un recuento incompleto $\gg . \quad L a \quad$ Jiribilla, No.364. Disponível em: <http://www.lajiribilla.co.cu/2008/n364_04/364_10.html>. Acesso: 5 de novembro de 2010.

AFP (Le 1er novembre 2010). "Sans réformes de son économie, Cuba va au «précipice», Cyberpress. Disponível em : <http://www.cyberpresse.ca/international/ameriquelatine/201011/01/014338171-sans-reformes-de-son-economie-cuba-va-au-precipice.php>. Acesso: 4 de novembro de 2010.

ARANGO, Arturo (2010). «Cuba, los intelectuales ante un futuro que ya es presente », Temas, octubre-diciembre 2010, No.64, pp. 80-90.

BAKER, Mona, y PÉREZ GONZÁLEZ, Luis (2011). Translation and Interpreting as Socially Situated Activities: Research Prospects and Challenges. Featured/Invited Colloquium at the American Association for Applied Linguistics (AAAL) 2011. Disponível em: <http://manchester.academia.edu/MonaBaker/Talks/37381/Translation_and_Interpreting_a s_Socially_Situated_Activities_Research_Prospects_and_Challenges>. Acesso: 14 de junho de 2012.

BASALAMAH, Salah (2005). «La traduction citoyenne n'est pas une métaphore », Dans: TTR, Vol. 18, No.2, Sherry Simon (dir) «Traduction engagée / Translation and Social Activism », pp. 49-69. Disponível em: < http://id.erudit.org/iderudit/015746ar>. Acesso: 29 de março de 2012.

(2010). " Por une (re)politisation de la traductologie », em Les Cultural Studies dans les mondes francophones. Dirigido por Boulou Ebanda de B'beri. Les Presses de l'Université d'Ottawa. p.123-144.

BASTIN, Georges L.; ECHEVERRI, Alvaro et CAMPO, A. (2004). " La traducción en América Latina: propia y apropiada.» Estudios. Revista de Investigaciones Literarias y Culturales. No.24. Caracas: Universidad Simón Bolívar, p.69-94.

BASTIN, Georges. L. (2010). « La pertinencia de los estudios históricos sobre traducción en Hispanoamérica. Estudios Interdisciplinarios de América Latina y el Caribe »Vol. 21, no. 1. Disponível em: <http://www1.tau.ac.il/eial/index.php?option=com_content\&task=view\&id=887\&Itemid 
=342>. Acesso: 15 de abril de 2011 .

BENESSAIEH, Afef (dir.) (2010). Transcultural Americas/Amériques Transculturelles, Ottawa: Les Presses de l'Université d'Ottawa. 261 p.

BOÉRI, Julie et MAIER, Carol. (dir.) (2009). Compromiso social y traducción/interpretación. Translation/interpreting and Social Activism. Granada: Ecos. 389 p.

BOURDIEU, Pierre (1994). Raisons pratiques : Sur la théorie de l'action. Paris: Seuil. $254 \mathrm{p}$.

BROWNLIE, Siobhan (2002). « La traduction de la terminologie philosophique ». Meta, XLVII, 3. p.296-310.

CANTY, Daniel () Atelier L'Écrivain numérique de l'UNEQ à Montreal. Disponível em : <http://www.uneq.qc.ca/documents/file/ecrvain-numerique.pdf>. Acesso: 5 de junho de 2011.

CASTRO RUZ, Fidel (1961). «Discurso pronunciado por el comandante Fidel Castro Ruz, Primer ministro del gobierno revolucionario y secretario del PURSC, como conclusión de las reuniones con los intelectuales cubanos, efectuadas en la Biblioteca nacional el 16, 23 y 30 de

118 junio 1961 », Discursos e intervenciones del Comandante en Jefe Fidel Castro Ruz. Disponível em: <http://www.cuba.cu/gobierno/discursos/1961/esp/f300661e.html>. Acesso: 13 de agosto de 2010.

(1968) « Castro Comments on Czechoslovak Crisis ». Havana Domestic Television and Radio Services in Spanish 0102 GMT 24 Aug 68. [Speech by Cuban Prime Minister Maj Fidel Castro on the Czechoslovak situation--live]. Disponível em: <http://lanic.utexas.edu/la/cb/cuba/castro/1968/19680824.html> Acesso: 20 de agosto de 2010. Este discurso não aparece ou foi retirado do sítio dos discursos de Castro. Disponível em: <http://www.cuba.cu/gobierno/discursos/>. Acesso: 20 de agosto de 2010.

CIA Factbook. Disponível em: <www.cia.gov/library/publications/the-worldfactbook/geos/cu.html>. Acesso: 7 de junho de 2011.

COLÓN RODRÍGUEZ, Raúl Ernesto, (2011) « La traduction de la pensée culturelle russe par Desiderio Navarro à Cuba, 1960-2009 » Tesis de maestría en traductología, Université d'Ottawa. Disponível em: <http://www.ruor.uottawa.ca/en/bitstream/handle/10393/20213/Col\%C3\%B3n_Rodrigue Z_Raul_Ernesto_2011_th\%C3\%A8se.pdf?sequence=1>. Acesso: 20 de maio de 2012.

CHAGUACEDA NORIEGA, Armando (2010). « La campana vibrante. Intelectuales, esfera pública y poder en Cuba: balance y perspectivas de un trienio (2007-2010) ». Cuadernos de 
Trabajo, no.37. Instituto de Investigaciones Histórico-Sociales. Universidad Veracruzana. $46 \mathrm{p}$.

CHARAUDEAU, Patrick et MAINGUENEAU, Dominique (dir.) (2002) Dictionnaire d'analyse du discours. Paris, Seuil. 666 p.

CRITERIOS, revista. Disponível em: <http://www.criterios.es>. Acesso: 2 de maio de 2012.

GARCÍA HERNANDEZ, Arturo (2007). «Pour une politique culturelle de Cuba, sans dogmes ni sectarismes ». Risal. Disponível em: 〈http://risal.collectifs.net/spip.php?article2160〉. Acesso: 27 de novembro de 2010.

GENTZLER, Edwin (2008). Translation and Identity in the Americas. New Directions in Translation Theory, London and New York: Routledge. 214 p.

FLEITES-LEAR, Marisela et PATTERSON, Enrique (1993). « Teoría y praxis de la revolución cubana. Apuntes críticos ». Nueva Sociedad, No.123. p. 50-64. Disponível em: <http://www.nuso.org/upload/articulos/2200_1.pdf>. Acesso: 23 de novembro de 2010.

FORNET, Ambrosio (2007). «El Quinquenio Gris : Revisitando el término », em NAVARRO, Desiderio et HERAS LEÓN, Eduardo. La política cultural del período revolucionario: memoria y reflexión, La Habana: Centro Teórico-Cultural Criterios, p.25-46.

LAGOS, José Gabriel (2011). "En la zona. La seducción de los discursos imperiales, según la investigadora Mary Louise Pratt", La diaria. Disponível em: <http://ladiaria.com/articulo/2011/4/en-la-zona/>. Acesso: 26 de maio de 2011.

LOTMAN, Iuri M. y NAVARRO, Desiderio, (trad. y ed.) (1996, 1998, 2000) La semiosfera, Madrid, Universitat de València, Frónesis Series, 3 Volúmenes.

MACHADO, Irene (2007) Semiotica da Cultura e Semiosfera, Annablume, 303 p.

MAALOUF, Amin (2001 [1998]). Les identités meurtrières, Paris: Le Livre de Poche. $189 \mathrm{p}$.

MORIN, Edgar (2005 [1990]). Introduction à la pensée complexe, Paris: Seuil. 158 p.

MESCHONNIC, Henri (1999). Poétique du traduire, Paris: Éditions Verdier. 480 p.

MIZROKHI, Elena (2009) « Néostalinisme: La fièvre rouge en Russie de Poutine », em Regard Politique, Université de Laval. Disponível em: <http://www.regardcritique.ulaval.ca/numeros_anterieurs/novembre_2009/neostalinisme _la_fievre_rouge_en_russie_de_poutine/>. Acesso : 3 de maio de 2012. 
NAVARRO, Desiderio (2002). « Criterios in medias res publicas » Criterios. Disponível em: <http://www.criterios.es/pdf/dncriteriosinmedias.pdf>. Acesso:11 de março de 2011.

NAVARRO, Desiderio (2006 [2000]). «In Medias res Publicas: Sobre los intelectuales y la crítica social en la esfera pública cubana », Las Causas de las Cosas, La Habana: Editorial Letras Cubanas, p.7-31. 189 p. Esse documento é a continuação de: «El papel del intelectual en la esfera pública”, Beirut: 24 al 25 de febrero del 2000. También en: La Gaceta de Cuba, (2001), La Habana: no 3, pp. 40-45; Ensayo cubano del siglo XX (2002) HERNANDEZ, Rafael y ROJAS, Rafael, Fondo de Cultura Económica, México: p. 689-707; Revista del CESLA (2002). Centro de Estudios Latinoamericanos, Universidad de Varsovia, n 4, Varsovia: p. 111-123. Em inglês: «Views from the South» (2001). Nepantla, Duke University, vol. 2, no 2, p. 355-371, y boundary 2 (2002). Duke University Press, vol. 29, n 3 (special issue From Cuba), p. 187-203.

NAVARRO, Desiderio (2007a). A pe(n)sar de todo. Para leer en contexto, La Habana: Editorial Letras cubanas, 335 p.

NAVARRO, Desiderio (2007b). « ¿Cuántos años de qué color? Para una introducción al Ciclo », en: NAVARRO, Desiderio et HERAS LEÓN, Eduardo. La política cultural del período revolucionario: memoria y reflexión, La Habana: Centro Teórico-Cultural Criterios, p. 15-24.

120 NAVARRO, Desiderio (2007c). «El debate en Cuba sobre Soledad Cruz: Desiderio Navarro versus Félix Sautié Mederos », Baracutey cubano,

<http://www.baracuteycubano.blogspot.com/2007/08/debates-sobre-soledad-cruz-y- su.html> (página consultada el 25 de abril del 2011).

NAVARRO, Desiderio (2009). El Pensamiento Cultural Ruso en criterios: 1972-2008. 2 volúmenes, La Habana: Centro Teórico Cultural Criterios, Vol 1: 343 p. Vol 2: 380 p.

ORTíZ, Fernando (1991 [1940]). Contrapunteo cubano del tabaco y el azúcar. La Habana: Editorial de Ciencias Sociales, 484 p.

PHILIPPE, Lançon (2007). "Carlos Victoria, digne jusque dans la mort », Libération. Disponível em: <http://www.liberation.fr/culture/0101113600-carlos-victoria-digne-jusque-dansla- mort>. Acesso: 3 de janeiro de 2011.

PRATT, Mary-Luise (2008 [1992]). Imperial Eyes: Travel Writing and Transculturation, London-New York: Routledge, 276 p.

SCARPETTA, Guy (1981). Éloge du cosmopolitisme, Paris: Grasset, 304 p.

SIMON, Sherry (1991). « La traduction et la traversée des savoirs », TTR, traduction, terminologie, rédaction, vol. $4, \mathrm{n}^{\circ} 2$.

COLÓN. Desiderio Navarro e a tradução da teoria crítica russa em Cuba

Belas Infiéis, v. 2, n. 2, p. 99-125, 2013. 
STALIN, Josif Visarionovich (1979 [1929]). « Sobre la desviación derechista en el PC(b) de la U.R.S.S. », en: STALIN, Josif V. (1929). Obras escogidas. Editorial Nentori, Tirana.

TYMOCZKO, Maria (2007). Enlarging Translation, Empowering Translators. Manchester: St. Jerome Publishing, 353 p.

(2010). Translation, Resistance and Activism, (Traducción, Resistencia y Activismo) University of Massachusetts Press, 299 p.

UNESCO (2005). « History and development [of Camagüey] ». Property for inscription on World Heritage Urban Historic Scenary Camagüey p.18-34. Disponível em: <http://whc.unesco.org/uploads/nominations/1270.pdf>. Acesso: 15 de dezembro de 2010.

VENUTI, Lawrence (2008 [1995]). The Translator Invisibility, A History of Translation, London-New York: Routledge, Second edition, 319 p.

WELSCH, Wolfgang (1999). «Transculturality - the Puzzling Form of Cultures Today », dans FEATHERSTONE, Mike et LASH, Scott (1999). Spaces of culture : city, nation, world. London: Thousand Oaks, Calif : Sage. pp. 194-213.

\footnotetext{
i Aqui politradutor se refere ao feito de Navarro traduzir a partir 14 línguas: inglês, francês, alemão, italiano, russo, polonês, húngaro, tcheco, servo-croata, eslovaco, romeno, búlgaro, esloveno e português. Disponível em: <http://www.criterios.es/autores/desiderio.htm>. Acesso em 26 de abril de 2011.

ii O termo do neostalinismo começa a ser usado à véspera da queda de Nikita Khrushchov, mas é atualmente é uma particularidade sabendo-se que na Rússia do presidente Vladimir Putin há o sentimento nostálgico com relação à era soviética, para assegura o apoio às políticas em curso. Além da Rússia, existem ilhotas seguidoras do neostalinismo, como Coréia do Norte e Cuba. (Ver: Mizrokhi, 2009). Um processo de reideologização de antigas sociedades comunistas, governadas por governantes publicamente neostalisnistas ou não, está ocorrendo. O reflexo da tradução nos processos de repolitização e de reideologização é o foco de um estudo em andamento no contexto de nossa pesquisa de doutorado.

iii Para consultar uma versão resumida da versão oficial dos acontecimentos em espanhol, verificar em: http://ipsnoticias.net/print.asp?idnews=39888. Acesso em 28 de maio de 2012.

iv No seminário L'Écrivain numérique da UNEQ [Sindicato dos escritores do Québec] em Montreal, seu organizador, o escritor Daniel Canty afirma: "En l'espace d'à peine une génération, la computation est devenue une dimension incontournable de la culture. L'ordinateur, cette machine logique universelle, est une puissante métaphore, qui transforme intimement nos visions du monde. [...] L'ordinateur, nouvelle machine à écrire est aussi une mirobolante machine à lire, qui chamboule l'univers de l'édition et de la diffusion littéraire". (Com diferença de somente uma geração, a computação se tornou algo insubstituível da cultura. O computado, essa máquina de lógica universal, é uma metáfora poderosa, que transforma intimamente nossa visão do mundo. [...] O computador, essa nova máquina de escrever é também um máquina de leitura estupenda, que modifica o mundo da publicação e da disseminação literária.) Verificar em: http://www.uneq.qc.ca/documents/file/ecrvain-numerique.pdf. Acesso em: 5 de junho de 2011.
}

COLÓN. Desiderio Navarro e a tradução da teoria crítica russa em Cuba

Belas Infiéis, v. 2, n. 2, p. 99-125, 2013. 
${ }^{v}$ Com exceção da Espanha, visto que é justamente neste país e não em Cuba que o site da revista Criterios, editada por Navarro, está hospedado desde a sua criação. Também foi basicamente na Espanha que Navarro pôde publicar várias de suas traduções e trabalhos teóricos numa época em que publicar em Cuba era praticamente impossível para ele. (COLÓN RODRÍGUEZ, 2011, p. 46).

vi Bourdieu o define como uma "série des positions successivement occupées par un même agent (ou un même groupe) dans un espace lui-même en devenir et soumis à d'incessantes transformations" (série de posições ocupadas sucessivamente por um mesmo agente (ou mesmo grupo) em um espaço ele próprio em devir e submetido a sucessivas transformações). (BOURDIEU, 1994, p. 88)

vii Pode-se afirmar, por exemplo, que o conhecimento e o estudo de Lotman na Espanha e de Baktin e Lotman no Brasil, se deve em parte pelo trabalho de tradução de Navarro. Ver: (LOTMAN \& NAVARRO, 1996, 1998, 2000) e (MACHADO, 2007). Além disso, a tradução da teoria da teoria culturológica russa foi o ponto de partida de diversos projetos de tradução de Navarro e do Centro-cultural Criterios.

viii 33 dos 115 textos teóricos russos sobre literatura, cinema, teatro, artes plásticas, estética e culturologia, traduzidos por Desiderio Navarro e publicados em El Pensamiento Cultural Ruso en critérios, 1972 - 2008. Centro TeóricoCultural Criterios, La Habana, 2009. Respeita-se aqui e em todo o mundo o documento da ortografia do título da antologia de Navarro, o qual tem uma intencionalidade bem definida.

ix Deve-se destacar que o Canadá teve lugar no colóquio Translation and Social Activism de 20 a 21 de outubro de 2005, na Universidade de York, em Toronto, organizado por Sherry Simon. Da Universidade de Ottawa, onde faço doutorado em tradutologia, teve-se comunicações de Luise com Flotow, "Interventionist film translation: Chicago in French", e outra de Salah Basalamah, "La traduction citoyene n'est pas une métaphore". Este último publicou recentemente outro artigo ligado a este tema, intitulado: "Pour une (re)polisation de la traductologie" 122 (BASALAMAH, 2010). Desde o ano de 2007, o tema da celebração do $1^{o}$ Fórum Internacional de Traducción/Interpretariado y Compromiso Social em Granada, Espanha, este tema teve importantes contribuições na literatura especializada (BOÉRI e MAIER, 2009). Ver: http://www.translationactivism.com. Acesso em: 20 de maio de 2011. O ativismo social dos tradutores teve posteriormente outros fóruns de discussão importantes, em particular, o colóquio Translation and Interpreting as Socially Situated Activities: Research Prospects and Challenges, realizado em 27 de março de 2011 e organizado por Mona Baker e Luis Pérez-González, do Centre for Translation and Intercultural Studies da Universidade de Manchester, Reino Unido. Uma última obra que merece ser mencionada, em relação à este tema, é a organizada por Maria Tymoczko (2010): Translation, Resistance and Activism, no qual a autora afirma: "thinking about translation and activism has moved beyond a focus on binaries in this domain as it has in most other areas of inquiry in translation studies, and thus it has moved beyond the focus on resistance " (pensar sobre tradução e ativismo mudou o foco para além do binarismo nessa área, como aconteceu nas demais áreas de investigação dos estudos da tradução, e, portanto, isto mudou o foco para além da resistência). (TYMOCZKO, 2010, p. viii)

${ }^{\mathrm{x}}$ Por antineocolonial se entende o termo que busca determinar os processos de luta política e social em curso na América Latina, a partir do deslocamento das antigas potências colônias europeias para os Estados Unidos, ocorrido entre os meados e o final do século XIX e definitivamente durante o século XX. Este termo foi proposto para contribuir com o debate em torno da terminologia dos estudos pós-coloniais, centralizados especialmente na Ásia e África. Neste sentido e a propósito da motivação do seu livro Imperial eyes: travel writing and transculturation, Mary Louise Pratt observou, em entrevista realizada na Argentina: "Tive um diálogo de muitos anos com Said. Minha reclamação com ele nunca foi acerca das Américas. No seu grupo não e aprendia espanhol nem era considerado necessário. Não consideraram como o fenômeno neocolonial aqui nem o fenômeno colonial na África e na Índia. E este foi um pouco o objetivo dos Olhos imperiais." (LAGOS, 2011).

xi Conhecido também, a "Geração de Mariel". Em 1980, um grande êxodo de cubanos para os Estados Unidos e outros países latino-americanos, como resultado dos eventos da Embaixada do Peru em Havana. Esse êxodo foi compostos principalmente por jovens nascidos nos anos 40 e 50, que a esta altura tinham entre 30 e 40 . Entre as 125

COLÓN. Desiderio Navarro e a tradução da teoria crítica russa em Cuba

Belas Infiéis, v. 2, n. 2, p. 99-125, 2013. 
mil pessoas que deixaram a ilha, havia um grande número de intelectuais, incluindo o famoso escritor Reinaldo Arenas. Ver: PHILIPPE, 2007.

xii Navarro menciona sua expulsão da universidade numa troca de mensagens com Felix Sautié, antigo alto funcionário da cultura de Cuba e executor das políticas de repressão dos intelectuais cubanos no período conhecido como "o quinquênio cinza" (NAVARRO, 2007c). A questão das expulsões das universidades cubanas ainda é relativamente um tabu para os cubanos da ilha, mas muito discutido no exílio (FLEITES-LEAR e PATTERSON, 1993). Mariela Castro Espín, uma representante oficial cubana, filha do atual presidente Raúl Castro e diretora do Centro Nacional de Educação Sexual de Cuba, se referiu a esta questão e sua declaração repercutiu em um dos sites oficiais do governo cubano (ACOSTA, 2009).

xiii Ver: nota I do presente artigo.

xiv Paradoxalmente, foi apenas recentemente, após 42 anos da implementação desta política no setor socioeconômico que o governo de Raúl Castro começou a autorizar novamente pequenas empresas familiares (AFP, 1 de novembro de 2010).

${ }^{x v}$ Stalin defendia em seu debate com Nikolai Bukharin que "na fase atual do desenvolvimento e devido à atual correlação das forças, a luta de classes se intensifica e aumenta a resistência dos elementos capitalistas da cidade e do campo. [...] As classes mais baixas não oferecem resistência porque são mais fortes do que nós, mas porque o socialismo cresce mais rapidamente do que eles, e estas são mais frágeis do que nós. E, justamente porque se fazem de mais frágeis, sentem que se aproxima a sua hora e se veem obrigadas a resistir com todas as forças, por todos os meios". (STALIN, 1929, p. 213-214)

xvi Primeiro como seção da revista La Gaceta de Cuba, logo como boletim independente e finalmente como revista a partir de 1982.

xvii Nesta antologia Navarro publicou traduções de artigos que eles havia publicado na revista Criterios de autores como Yuri M. Lotman, Miklós Szabolcsi, Abraham A. Moles, Henryk Markiewicz, Umberto Eco, Mikhail Bakhtin, Jan Mukařovský, entre outros. Ver: <http://www.criterios.es/masalla/iii19.htm>. Acesso em: 4 de maio de 2012.

xviii Uma lista não atualizada das publicações desta coleção editorial está disponível no sítio da revista on-line: <http://www.criterios.es/coleccion.htm>. Acesso: 4 de maio de 2012.

xix Navarro reconhece em seu prólogo da antologia do pensamento russo que Critérios teve que recorrer a criptopolêmicas contra os detentores da doxa. (NAVARRO, 2009, p. xxvi)

${ }^{\mathrm{xx}}$ Revista universitária que, desde os pressupostos ideológicos da esquerda e com uma clara preferência por essa tendência política, publicou centenas de artigos dos principais autores clássicos e contemporâneos sobre temas filosóficos, sociopolíticos e sociológicos. Esta revista foi proibida pelo governo cubano em 1971, no marco da sovietização dos centros de ensino universitários e da vida cultural do país em geral. Ao invés da diversidade teórica da qual Pensamiento Crítico era um representante formidável, o que ocorreu foi uma introdução massiva do marxismo ortodoxo soviético.

xxi O próprio Navarro nos explica, em nota de rodapé, acerca do termo: "Pavonato, nome que se deu ao período (1971 - 1976) em que Luis Pavón Tamayo exerceu o cargo de Presidente do Conselho Nacional de Cultura" (NAVARRO, 2007b, p.16). O termo foi uma sarcástica e direta alusão à douta ignorância dos teóricos dominantes até então.

xxii União Nacional dos Escritores e Artistas de Cuba. Organização para-oficial que consagra ou desaprova artistas e intelectuais cubanos e administra suas finanças.

xxiii Casa de las Américas é uma instituição cultural cubana que "divulga, investiga, patrocina, premia e publica o trabalho de escritores, artistas plásticos, músicos, dramaturgos e estudiosos da literatura e das artes; cuja comunicação

COLÓN. Desiderio Navarro e a tradução da teoria crítica russa em Cuba

Belas Infiéis, v. 2, n. 2, p. 99-125, 2013. 
fomenta o intercâmbio com instituições e pessoas de todo o mundo". Ver a apresentação no sítio da instituição: <http://www.casa.cult.cu/>. Acesso em: 24 de maio de 2011.

xxiv Uma série de três artigos de Desiderio Navarro intitulado "El obsceno encanto del cinismo" em resposta ao artigo do jovem curador de exposições Piter Ortega, intitulado "Desiderio Navarro y el Partido de los Mocos Verdes (o La estratégia del camaleón)", publicados em julho de 2010. Este intercâmbio foi compartilhado por Navarro com a lista de assinantes das mensagens de Criterios. Pode-se encontrar também em: <http://www.penultimosdias.com/2010/07/22/33937/>. Acesso em: 6 de junho de 2012.

xxv "Criterios: Uma ventana al mundo", 6 de fevereiro de 1989, texto que foi apresentado no II Encontro Internacional de Criterios e "Criterios in medias res publicas", conferência apresentada em 28 de fevereiro de 2002 na Casa de las Américas, em La Habana, em ocasião do $30^{\circ}$ aniversário da revista e do $80^{\circ}$ aniversário de Yuri Lotman. http://www.criterios.es/presentacion.htm. Acesso em: 14 de fevereiro de 2011.

xxvi "Dentro da Revolução, tudo; contra a Revolução, nada". (CASTRO, 1961)

xxvii Navarro teve que escolher diversas vezes entre a ajuda do Estado, (a condição de realizar um trabalho que não seja contestatório do sistema), e o trabalho que realiza acompanhado de uma delicada dose de denúncia (em função das circunstâncias), mas sem uma ajuda estatal. Nesta correlação de forças conseguiu construir em lugar na esfera pública cubana e não é de hoje, mais ou menos tolerado, ajudado até certo ponto pelos atores da vida cultural oficial e detestado ou sabotado por outros. De todos Navarro testemunha no prólogo da antologia estuda aqui e em outros textos que se publicou.

xxviii Instituto cubano das Artes e Indústria cinematográfica.

124 xxix Navarro publicou em Criterios diversos textos originais e traduções de textos de Bourdieu. A utilização frequente que ele faz em seus escritos dos conceitos bourdieusianos permite considerá-lo como um autor fortemente influenciado pelo pensamento do célebre sociólogo francês. Uma análise mais detalhada a respeito da terminologia nos textos de Navarro pode ser encontrada no segundo capítulo da tese no início do presente texto. Ver: (Colón Rodríguez, 2011:70-79).

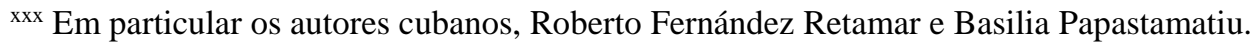

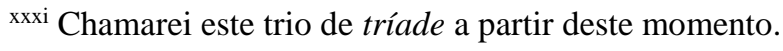

xxxii No primeiro volume da antologia foram publicadas 16 traduções recentes (anos 1993-2008) nas quais contam-se 58 notas de rodapé do tradutor. O segundo volume conta com 17 traduções dos anos 1972-1993 nas quais contam-se 46 notas do tradutor. Uma análise integral dos 115 textos de teoria russa traduzidos por Navarro permitiria confirmar essa hipótese.

xxxiii É conhecido, por exemplo, que no campo da literatura e da poesia, durante certos períodos da história da tradução no Ocidente, ou em culturas como a anglo-saxônica de maneira mais permanente, tem sido tradição entre os tradutores a domesticação (domestication) do texto de partida e desde a busca de estilos preexistentes na literatura e cultura de chegada para expor melhor o texto estrangeiro. Apesar de os esforços de tradutores-tradutólogos como Lawrence Venuti para favorecer a estrangeirização (foreignization) na sua tríade de chegada: a anglófona, esse tipo de tradução não tem desfrutado de êxito comercial, isto é, o esforço continua sendo marginal. (Venuti, 2008 [1995]:125-163).

xxxiv Siobhan Brownlie observa que « une approche contextuelle et sociologique s'avère donc nécessaire pour comprendre l'élaboration et le fonctionnement des termes, non seulement dans l'étude de la terminologie. (Voir Boulanger 1995), mais aussi dans l'étude de la traduction de la terminologie. " (uma abordagem sociológica e contextualizada é necessária para compreender a elaboração e funcionamento dos termos, não somente no estudo da terminologia (ver Boulanger 1995), mas também no estudo da tradução da terminologia) (Brownlie, 2002:308).

COLÓN. Desiderio Navarro e a tradução da teoria crítica russa em Cuba

Belas Infiéis, v. 2, n. 2, p. 99-125, 2013. 
xxxv Maria Tymoczko afirma, a respeito da transculturação em Cuba e na Irlanda: "The transculturations that shaped culture in Cuba and Ireland are similar in many ways to the massive transculturation currently occurring around the world as a consequence of globalization" (as transculturações que marcaram as culturas de Cuba e Irlanda são similares em muitos sentidos à transculturação massiva que vem ocorrendo no mundo de hoje como consequência da globalização) (Tymoczko, 2007:124). Esta afirmação ilustra o estreito vínculo existente entre a identidade transcultural e a condição pós-colonial. Tymoczko também sublinhou neste texto a importância do conceito de transculturação para a tradutologia. Ela afirma que: "For translation studies the concept of transculturation is important because it illuminates certain performative types of translations that function primarily to insert elements from one culture into another" (Para os estudos da tradução, o conceito da transculturação é importante porque ilumina certos tipos performativos de tradução cuja função primária é inserir elementos de uma cultura em outra), (Tymoczko, 2007:125).

xxxvi Segundo Maria Tymoczko o termo "transculturação" em inglês obteve uma "ampla circulação" nos estudos literários anglófonos, já na publicação deste livro de Pratt (Tymoczko, 2007:120).

xxxvii Em Cuba o anti-imperialismo, é a linha política fundamental da política exterior do país (ver: <http://america.cubaminrex.cu/Ministerio/ministerio.htm> (página consultada em 16 de abril de 2011), mas o termo antineocolonialismo me parece mais adequado ao contexto atual, porque permite identificar outras facetas da condição estudada e não somente o antagonismo cubano com os Estados Unidos. Permite igualmente vislumbrar outra condição relacionada, a pós-neocolonial, em continuidade e ruptura com a primeira. Continuidade em certos traços característicos: apego à soberania nacional, por exemplo. Ruptura, nos meios de comunicação para garantir essa soberania e nos critérios acerca da vida social, em particular a liberdade de expressão.

xxxviii Bastin refina essa definição nos dois artigos citados afirmando que se trata de uma: "modalidade criativa da tradução que tende a consolidar a identidade da coletividade a qual pertence o tradutor » (Bastin e col. 2004:72 e Bastin, 2010).

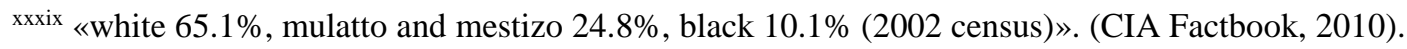

xl Sabe-se que a filosofia e a política marxistas promovem "o internacionalismo proletário" como princípio básico. Este princípio tem sido invocado pelas autoridades cubanas seguindo as aventuras militares extracontinentais (particularmente Angola), mas a ideologia nacionalista foi invocada com muito mais frequência quando se fala de defender ou justificar, no interior do país, decisões divergentes dos países "irmãos" aliados, como fora a União Soviética, o campo socialista, ou o que ainda é, em certa medida, na China.

xli "Serviço informativo bimestral de pensamento cultural europeu". Primeiro correio eletrônico recebido em $1^{\circ}$ de fevereiro de 2011. Navarro já enviou para sua lista de correio eletrônicos 27 números do Serviço Informativo, (Informação atualizada em 15 de junho de 2012).

COLÓN. Desiderio Navarro e a tradução da teoria crítica russa em Cuba Belas Infiéis, v. 2, n. 2, p. 99-125, 2013. 